\title{
CORRESPONDENCE
}

\section{CHESS COMPUTERS AND ENDGAME STUDIES 4}

\author{
John Nunn
228, Dover House Road
London, SW15 5AH
Great Britain

Further to the letters by Whyld and Proskurowski in the June 1992 issue of the ICCA Journal, which commented on Brian Gosling's article, I too had noticed this article when it appeared in EBUR and Chess. I sent a letter to Chess making many of the same points as given in the Whyld and Proskurowski letters. However there was one additional point which the other letters failed to mention, namely that Mr. Gosling's correction to the unsound Platov study is itself unsound:

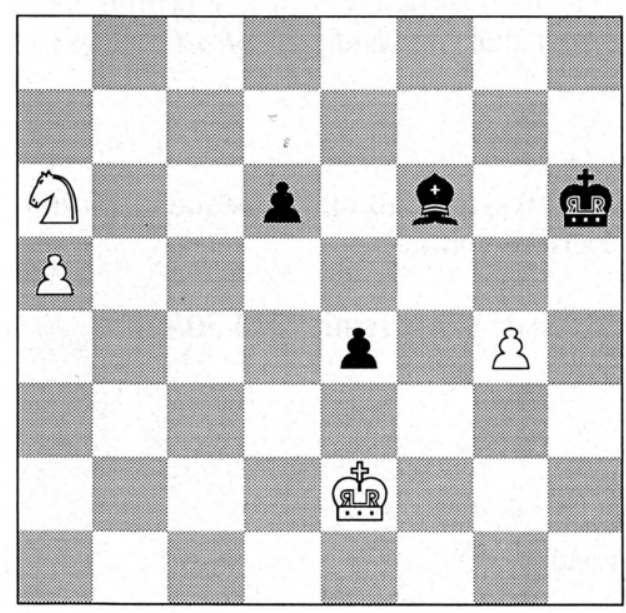

It is also worth adding that Mr. Gosling didn't correct the Korolkov study, he simply reversed the colours, whereupon the main line became a boring piece of endgame technique while Korolkov's spectacular intention was relegated to a sub-variation arising only after faulty play. Korolkov's 1954 prize-winner was, by contrast, a genuine correction.
The intended solution is 1 . g5+, but White has an alternative technical win by 1 . Nc5 Bd4 2. Nxe4 d5 3. Nd6 $\mathrm{Bc5}$ 4. a6 d4 (4.... Kg5 5. Kf3 is even worse) 5 . Ne4 Ba7 6. $\mathrm{Kd} 3$ (there are many other ways to win, but this gives Black the least choice) Kg6 7. Kc4 Kh6 8. Kd5 Kg6 9. Kc6 d3 10. Kd5 Kh6 11. Kc4 d2 12. Nxd2 Kg5 13. Kd5 Kxg4 14. Kc6 Kf5 15. Kb7 Bg1 16. Nc4 Ke6 17. Nb6 and wins.

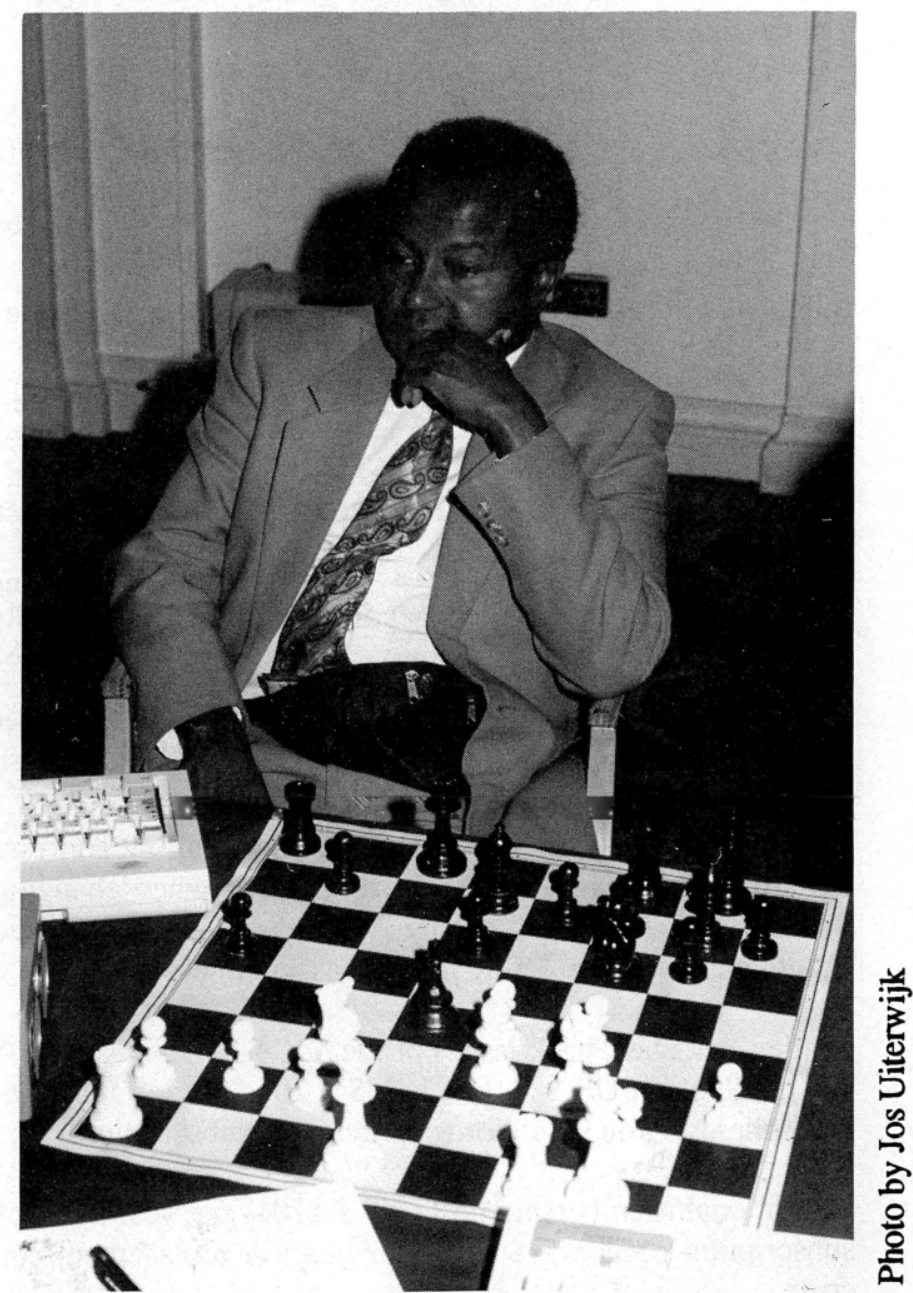

LEAN OVER BACKWARDS.

Walter Bannerman (Ananse), Londen, August 1992. 